\title{
KEMAMPUAN MENULIS TEKS BIOGRAFI SISWA KELAS VIII SMP NEGERI 2 KOTA SOLOK
}

\author{
Mega Putri \\ Melia Rahmadona \\ Universitas Mahaputra Muhammad Yamin Solok Sumbar
}

\begin{abstract}
This research is motivated by several things, namely, when research and informal interviews with subject teachers Indonesian-class VIII SMP Negeri 2 Kota Solok on August 11, 2014 and December 24, 2014, there are several problems students lack interest in writing as Each student is assigned to write, students who complain, in the students' many words in a shortshorted, disadvantaged students in writing the text in accordance with the structure, because the text students many are not able to formulate the text fit the actual structure, This type of research is quantitative descriptive method. This method is called quantitative methods for research data in the form of figures and analysis using statistics. Data are analyzed test results, test the performance of writing a text biography. Based on the research that has been done, test the student's ability to write a text biography based on the qualifications structure orientation is more than enough (LDC) with an average of 72.58. The ability of students to write a text biography based on the structure of events / issues are on the qualifications More than Enough (LDC) with an average of 67.74. The ability of students to write a biography of text according to the qualification structure of the reorientation is Enough $(C)$ with an average of 62.09. Based on the research that has been described in Chapter IV, it can be concluded that the first semester of eighth grade students of SMP Negeri 2 Kota Solok in the academic year 2015/2016 in writing the text of the biography is based on the structure of the text was able to write a text biography of qualification More than Enough (LDC) with a mean value -rata 69.57.
\end{abstract}

Keywords: Ability Writing, Text Biography, SMPN 2 Solok.

\begin{abstract}
ABSTRAK
Penelitian ini dilatarbelakangi oleh beberapa hal, yaitu, ketika wawancara informal dengan guru mata pelajaran Bahasa Indonesia kelas VIII SMP Negeri 2 Kota Solok pada tanggal 11 Agustus 2014 dan 24 Desember 2014, ada beberapa masalah siswa kurang berminat dalam menulis sebagai Setiap siswa ditugaskan untuk menulis, siswa yang mengeluh, dalam banyak kata-kata siswa dalam pendek korsleting, siswa yang kurang beruntung dalam menulis teks sesuai dengan struktur, karena siswa teks banyak yang tidak mampu merumuskan teks sesuai dengan struktur yang sebenarnya, Jenis penelitian ini adalah metode deskriptif kuantitatif. Metode ini disebut metode kuantitatif untuk data penelitian dalam bentuk angka dan analisis menggunakan statistik. Data dianalisis hasil tes, menguji kinerja menulis biografi teks. Berdasarkan penelitian yang telah dilakukan, menguji kemampuan siswa untuk menulis biografi teks berdasarkan orientasi kualifikasi struktur lebih cukup (LDC) daripada dengan rata-rata 72,58. Kemampuan siswa untuk menulis biografi teks berdasarkan struktur peristiwa / masalah yang kualifikasi Lebih dari Cukup (LDC) dengan rata-rata 67,74. Kemampuan siswa untuk menulis biografi teks sesuai dengan struktur kualifikasi reorientasi adalah Cukup (C) dengan rata-rata 62,09. Berdasarkan penelitian yang telah dijelaskan pada Bab IV, dapat
\end{abstract}


disimpulkan bahwa semester pertama siswa kelas VIII SMP Negeri 2 Kota Solok pada tahun akademik 2015/2016 dalam menulis teks biografi didasarkan pada struktur teks mampu menulis biografi teks kualifikasi Lebih dari Cukup (LDC) dengan nilai rata -rata 69,57.

Kata kunci: Kemampuan Menulis, Teks Biografi, SMPN 2 Solok.

\section{PENDAHULUAN}

Semua pelajaran Bahasa Indonesia mulai jenjang Sekolah Dasar (SD) sampai dengan Sekolah Menengah Atas (SMA) pada kurikulum 2013 sangat berbeda dengan kurikulum 2006. Pada kurikulum 2013 ini pembelajaran bahasa Indonesia berbasis teks. Pembelajaran berbasis teks, siswa menggunakan bahasa tidak saja hanya dijadikan sebagai sarana komunikasi, tetapi sebagai sarana mengembangkan kemampuan berpikir. Oleh karena itu, pembelajaran berbasis teks ini perlu segera dipahami oleh pemerhati pengajaran Bahasa Indonesia, guru Bahasa Indonesia, mahasiswa, dan pihak-pihak yang terkait.

Pengertian teks dalam kurikulum ini berbeda dengan pengertian teks selama ini. Teks selama ini diartikan sebagai wacana tertulis. Berdasarkan kurikulum
2013 teks tidak diartikan sebagai bentuk bahasa tulis. Teks itu adalah ungkapan pikiran manusia yang lengkap yang di dalamnya ada situasi dan konteksnya. Teks dibentuk oleh konteks situasi penggunaan bahasa yang di dalamnya ada register atau ragam bahasa yang melatar belakangi lahirnya teks tersebut.

\section{Berdasarkan kurikulum selama ini} yang selalu memperhatikan adanya pembelajaran kemampuan berbahasa dan kemampuan bersastra, maka teks dalam Kurikulum 2013 dapat juga dibedakan antara teks sastra dan teks nonsastra. Kurikulum 2013 tidak menjelaskan secara rinci bagaimana pendekatan pembelajaran Bahasa Indonesia termasuk sastra sebagaimana pada kurikulum sebelumnya.Maka membahas substansi teks dalam kurikulum ini hanya berdasarkan interpretasi terhadap 
kompetensi dasar dalam mata pelajaran Bahasa Indonesia.

$$
\text { Pembelajaran nonsastra yang }
$$

dihadirkan dalam bentuk kegiatan menulis teks biografi menuntut siswa agar mampu menulis teks biografi sesuai dengan strukturnya. Teks biografi adalah teks yang mengisahkan tokoh atau pelaku, peristiwa dan masalah yang dihadapinya. Tujuan teks biografi adalah untuk mengetahui riwayat hidup seorang tokoh, yang berisikan paparan perjalanan hidup, perjuangan karya, dan penghargaan yang didapatkannya.

Teks biografi adalah teks paparan yang ditulis oleh orang lain. Teks ini ditulis dengan tujuan menyampaikan hal-hal yang dapat dijadikan keteladanan dari orang tersebut. Teks biografi ini biasanya merupakan teks pemaparan dari tokohtokoh terkenal. Proses penyusunan teks ini pun tidak sembarangan melainkan melalui pencarian data-data yang akurat. Menurut Susanto (2014: 217-219), struktur teks biografi sebagai berikut: (1) Orientasi, merupakan bagian awal dari sebuah teks biografi yang menceritakan mengenai tempat dan tanggal lahir tokoh serta masa kecil tokoh, (2) Peristiwa atau masalah, dalam teks biografi, peristiwa atau masalah dapat di tuliskan menjadi beberapa paragraf dan berisi peristiwa hebat dan menakjubkan yang pernah dialami tokoh, (3) Reorientasi, merupakan penutup dalam teks biografi. Reorientasi biasanya berisi opini si Penulis dan biasanya bersifat opsional (bisa ada atau tidak).

Materi mengenai menulis teks biografi terdapat dalam pembelajaran di sekolah, khususnya di kelas VIII pada semester I kurikulum 2013. Berdasarkan silabus mata pelajaran Bahasa Indonesia yang sesuai dengan kurikulum 2013, salah satu tema pembelajaran Bahasa Indonesia adalah teks biografi.

Berdasarkan observasi awal dan wawancara informal dengan guru mata pelajaran Bahasa Indonesia kelas VIII SMP Negeri 2 Kota Solok pada tanggal 11 Agustus 2014 sampai 24 Desember 2014, 
terdapat beberapa permasalahan siswa kurang minat dalam menulis, hal ini terlihat pada saat siswa latihan menulis, siswa banyak menyingkat-nyingkat kata, siswa kurang mampu dalam menulis teks sesuai dengan struktur, karena siswa tidak memahami struktur yang benar. Berdasarkan latar belakang masalah di atas, dapat didentifikasi beberapa permasalahan, antara lain: 1. Siswa kurang minat dalam menulis, karena terlihat pada saat siswa latihan menulis, siswa banyak menyingkat-nyingkat kata, 2. Siswa kurang mampu dalam menulis teks, karena siswa tidak memahami struktur yang benar.

Berdasarkan identifikasi masalah di atas peneliti membatasi penelitian ini pada masalah kemampuan menulis teks biografi siswa kelas VIII SMP Negeri 2 Kota Solok. Berdasarkan batasan masalah di atas rumusan masalah penelitian ini adalah bagaimanakah kemampuan menulis teks biografi siswa kelas VIII SMP Negeri 2 Kota Solok? Berdasarkan rumusan masalah di atas, tujuan penelitian ini adalah untuk mendeskripsikan kemampuan menulis teks biografi siswa kelas VIII SMP Negeri 2 Kota Solok.

\section{METODE PENELITIAN}

Jenis penelitian ini adalah kuantitatif dengan menggunakan metode deskriptif. Menurut Arikunto (2010: 173), populasi adalah keseluruhan subjek penelitian. Populasi penelitian ini adalah siswa kelas VIII SMP Negeri 2 Kota Solok yang terdaftar pada tahun pelajaran 2015/2016. Jumlah siswa terbagi menjadi sebelas kelas dengan jumlah keseluruhan 310 orang. Menurut Arikunto (2010: 174) sampel adalah sebagian atau wakil populasi yang diteliti. Pada penelitian ini penulis menetapkan sampel sebanyak $10 \%$ dari populasi, sehingga sampel berjumlah 31 orang tersebar di semua kelas.

Instrumen yang digunakan dalam penelitian ini adalah tes, tes berupa unjuk kerja dalam bentuk teks biografi. Arikunto (2013: 66), tes adalah alat atau prosedur yang digunakan untuk mengetahui atau 
mengukur sesuatu dalam suasana, dengan cara dan aturan-aturan yang sudah ditentukan.

Data yang akan dianalisis yaitu hasil tes, penganalisisan hasil tes yang telah terkumpul dianalisis melalui tahaptahap berikut:

1. Mengoreksi hasil tulisan siswa.

2. Memberikan skor hasil tes yang telah dikerjakan siswa.

3. Mengubah skor mentah menjadi nilai. Menurut Nurgiyantoro (dalam Abdurahman dan Ellya Ratna, 2003: 26), untuk mengubah skor menjadi nilai digunakan rumus sebagai berikut:

$\mathrm{N}=\frac{S M}{S I} \times \mathrm{S}_{\text {maks }}$

Keterangan:

$\mathrm{N}=$ Tingkat Penguasaan

$\mathrm{SM}=$ Skor yang diperoleh

SI = Skor Ideal / skor yang dicapai dalam suatu tes

$S_{\text {maks }}=$ Skala yang digunakan (100)
4. Mengelompokkan penentuan patokan dengan perhitungan persentase untuk skala 10

5. Membuat histogram kemampuan menulis teks biografi siswa.

6. Menafsirkan kemampuan menyusun teks biografi siswa berdasarkan rata-rata hitung. Untuk menentukan rata-rata hitung menurut Nurgiyantoro (dalam Abdurahman dan Ellya Ratna, 2003:265) digunakan rumus:

$$
M=\frac{\sum F X}{N}
$$

Keterangan:

\begin{tabular}{|c|c|c|c|}
\hline No & $\begin{array}{c}\text { Tingkat } \\
\text { Penguasaan }\end{array}$ & $\begin{array}{c}\text { Nilai } \\
\text { Ubahan }\end{array}$ & Kualifikasi \\
\hline 1. & $96 \%-100 \%$ & 10 & Sempurna \\
\hline 2. & $86 \%-95 \%$ & 9 & Baik sekali \\
\hline 3. & $76 \%-85 \%$ & 8 & Baik \\
\hline 4. & $66 \%-75 \%$ & 7 & Lebih dari cukup \\
\hline 5. & $56 \%-65 \%$ & 6 & Cukup \\
\hline 6. & $46 \%-55 \%$ & 5 & Hampir cukup \\
\hline 7. & $36 \%-45 \%$ & 4 & Kurang \\
\hline 8. & $26 \%-35 \%$ & 3 & Kurang sekali \\
\hline 9. & $16 \%-25 \%$ & 2 & Buruk \\
\hline Bidgraf & Siswa Kt5\% VIII $\$$ MP Negeri 2 Korurds 1 \&kkali \\
\hline
\end{tabular}




$$
\begin{aligned}
& M=\text { Mean/rata-rata } \\
& F=\text { Frekuensi } \\
& X=\text { Skor } \\
& N=\text { Jumlah Sampel }
\end{aligned}
$$

7. Membahas hasil analisis data dan membuat simpulan.

\section{HASIL DAN PEMBAHASAN}

\section{Deskripsi dan Analisis Data}

Data penelitian ini dikumpulkan melalui tes. Tes dilaksanakan pada hari Jumat, tanggal 7 Agustus 2015 dengan alokasi waktu 2 x 40 menit. Penelitian ini dilaksanakan pada setiap kelas VIII SMP Negeri 2 Kota Solok Semester I. Data penelitian ini adalah 31 orang. Tes pada kelas ini berupa tes menulis teks biografi. Bentuk pembelajaran pada kelas ini, pembelajaran diawali dengan membuka pelajaran, menjelaskan materi, dan memberikan tes kepada siswa. Setelah tulisan siswa terkumpul lalu diolah berdasarkan struktur teks biografi.

Tabel 2. Skor Penilaian Kemampuan Siswa Menulis Teks Biografi Siswa Kelas VIII SMP Negeri 2 Kota Solok

\begin{tabular}{|c|c|c|c|c|c|c|c|c|c|c|}
\hline \multirow{2}{*}{ NKS } & \multicolumn{2}{|c|}{ O } & \multicolumn{2}{c|}{ P/M } & \multicolumn{2}{c|}{ R } & P & $\begin{array}{c}\text { Skor } \\
\text { total }\end{array}$ & Nilai & \multirow{2}{*}{ KL } \\
\cline { 2 - 11 } & $\mathbf{P}$ & S & $\mathbf{P}$ & S & $\mathbf{P}$ & $\mathbf{S}$ & & & & \\
\hline 001 & 2 & 2 & 2 & 2 & 2 & 2 & 6 & 6 & 50 & HC \\
\hline 002 & 2 & 2 & 4 & 4 & 1 & 1 & 7 & 7 & 58,33 & HC \\
\hline 003 & 2 & 2 & 1 & 1 & 3 & 3 & 6 & 6 & 50 & HC \\
\hline 004 & 4 & 4 & 3 & 3 & 1 & 1 & 8 & 8 & 66,66 & LDC \\
\hline 005 & 4 & 4 & 4 & 4 & 1 & 1 & 9 & 9 & 75 & LDC \\
\hline 006 & 4 & 4 & 3 & 3 & 1 & 1 & 8 & 8 & 66,66 & LDC \\
\hline 007 & 4 & 4 & 2 & 2 & 3 & 3 & 9 & 9 & 75 & LDC \\
\hline 008 & 2 & 2 & 2 & 2 & 4 & 4 & 10 & 10 & 66,66 & LDC \\
\hline 009 & 2 & 2 & 3 & 3 & 4 & 4 & 9 & 9 & 75 & LDC \\
\hline 010 & 4 & 4 & 3 & 3 & 1 & 1 & 8 & 8 & 66,66 & LDC \\
\hline
\end{tabular}




\begin{tabular}{|c|c|c|c|c|c|c|c|c|c|c|}
\hline 011 & 2 & 2 & 3 & 3 & 3 & 3 & 8 & 8 & 66,66 & LDC \\
\hline 012 & 3 & 3 & 3 & 3 & 2 & 2 & 8 & 8 & 66,66 & LDC \\
\hline 013 & 3 & 3 & 4 & 4 & 4 & 4 & 11 & 11 & 91,66 & BS \\
\hline 014 & 2 & 2 & 2 & 2 & 2 & 2 & 6 & 6 & 50 & $\mathrm{HC}$ \\
\hline 015 & 4 & 4 & 3 & 3 & 1 & 1 & 8 & 8 & 66,66 & LDC \\
\hline 016 & 4 & 4 & 4 & 4 & 4 & 4 & 12 & 12 & 100 & $S$ \\
\hline 017 & 4 & 4 & 4 & 4 & 4 & 4 & 12 & 12 & 100 & $S$ \\
\hline 018 & 3 & 3 & 2 & 2 & 2 & 2 & 7 & 7 & 58,33 & C \\
\hline 019 & 2 & 2 & 2 & 2 & 3 & 3 & 7 & 7 & 58,33 & C \\
\hline 020 & 2 & 2 & 2 & 2 & 4 & 4 & 8 & 8 & 66,66 & LDC \\
\hline 021 & 2 & 2 & 2 & 2 & 3 & 3 & 7 & 7 & 58,33 & C \\
\hline 022 & 2 & 2 & 2 & 2 & 3 & 3 & 7 & 7 & 58,33 & C \\
\hline 023 & 2 & 2 & 2 & 2 & 4 & 4 & 8 & 8 & 66,66 & LDC \\
\hline 024 & 2 & 2 & 3 & 3 & 1 & 1 & 6 & 6 & 50 & $\mathrm{HC}$ \\
\hline 025 & 2 & 2 & 1 & 1 & 2 & 2 & 5 & 5 & 41,66 & K \\
\hline 026 & 3 & 3 & 2 & 2 & 1 & 1 & 4 & 4 & 50 & $\mathrm{HC}$ \\
\hline 027 & 3 & 3 & 2 & 2 & 4 & 4 & 9 & 9 & 75 & LDC \\
\hline 028 & 4 & 4 & 4 & 4 & 1 & 1 & 9 & 9 & 75 & LDC \\
\hline 029 & 4 & 4 & 4 & 4 & 3 & 3 & 11 & 11 & 91,66 & BS \\
\hline 030 & 4 & 4 & 4 & 4 & 4 & 4 & 12 & 12 & 100 & $S$ \\
\hline 031 & 3 & 3 & 2 & 2 & 1 & 1 & 6 & 6 & 50 & $\mathrm{HC}$ \\
\hline Jumlah & & & & & & & & & 2156,91 & \\
\hline $\begin{array}{c}\text { Rata- } \\
\text { rata }\end{array}$ & & & & & & & & & 69,57 & \\
\hline
\end{tabular}

\section{Keterangan:}

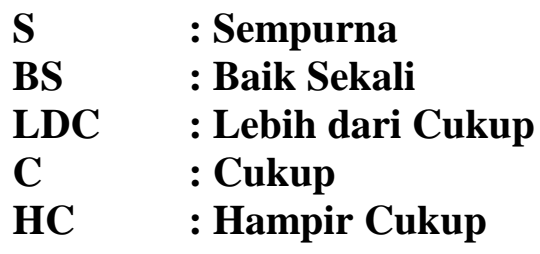


K : Kurang

Berdasarkan data tabel 2 di atas, diperoleh kemampuan siswa menulis teks biografi pada kualifikasi Lebih dari Cukup (LDC) dengan rata-rata 69,57. Perolehan skor tertinggi 12 dan terendah 5 dari skor maksimal 12 berdasarkan penulisan teks biografi. Secara lengkap kemampuan siswa menulis teks biografi sesuai dengan struktur sebagai berikut: (1) skor 12 sebanyak 3 orang $(9,67 \%)$, (2) skor 11 sebanyak 2 orang $(6,45 \%)$, (3) skor 9 sebanyak 5 orang $(16,12 \%)$, (4) skor 8 sebanyak 9 orang $(29,03 \%)$, (5) skor 7 sebanyak 5 orang $(16,12 \%)$, (6) skor 6 sebanyak 6 orang (19,35\%), dan (7) skor 5 sebanyak 1 orang $(3,22 \%)$.

Tabel 3. Persentase Pengualifikasian Kemampuan Siswa Menulis Teks Biografi dengan Kelas VIII SMP Negeri 2 Kota Solok dengan Menggunakan Skala 10

\begin{tabular}{|l|l|l|l|l|}
\hline No & Tingkat Penguasaan & Nilai & Frekuensi & Kualifikasi \\
\hline 1 & $96-100 \%$ & 10 & 3 & Sempurna \\
2 & $86-95 \%$ & 9 & 2 & Baik sekali \\
3 & $76-85 \%$ & 8 & 0 & Baik \\
4 & $66-75 \%$ & 7 & 14 & Lebih dari Cukup \\
5 & $56-65 \%$ & 6 & 4 & Cukup \\
6 & $46-55 \%$ & 5 & 7 & Hampir Cukup \\
7 & $36-45 \%$ & 4 & 1 & Kurang \\
8 & $26-35 \%$ & 3 & 0 & Kurang Sekali \\
9 & $16-25 \%$ & 2 & 0 & Buruk \\
10 & $0-15 \%$ & 1 & 0 & Buruk Sekali \\
\hline & Jumlah & & 31 & \\
\hline
\end{tabular}


Terlihat dari tabel 3 di atas dapat diketahui nilai sampel dalam skala 10 sebagai berikut. Nilai 10 diperoleh oleh 3 sampel $(9,67 \%)$, nilai 9 diperoleh oleh 2 sampel $(6,45 \%)$, nilai 7 diperoleh oleh 14 sampel $(45,16 \%)$, nilai 6 diperoleh 4 sampel $(12,90 \%)$, nilai 5 diperoleh 7 sampel $(22,58 \%)$, nilai 4 diperoleh 1 sampel $(3,22 \%)$, sedangkan nilai, 8, 3, 2 dan 1 di peroleh 0 sampel. Lebih jelas hasil kemampuan siswa menulis teks biografi dapat digambarkan dengan histogram di bawah ini.

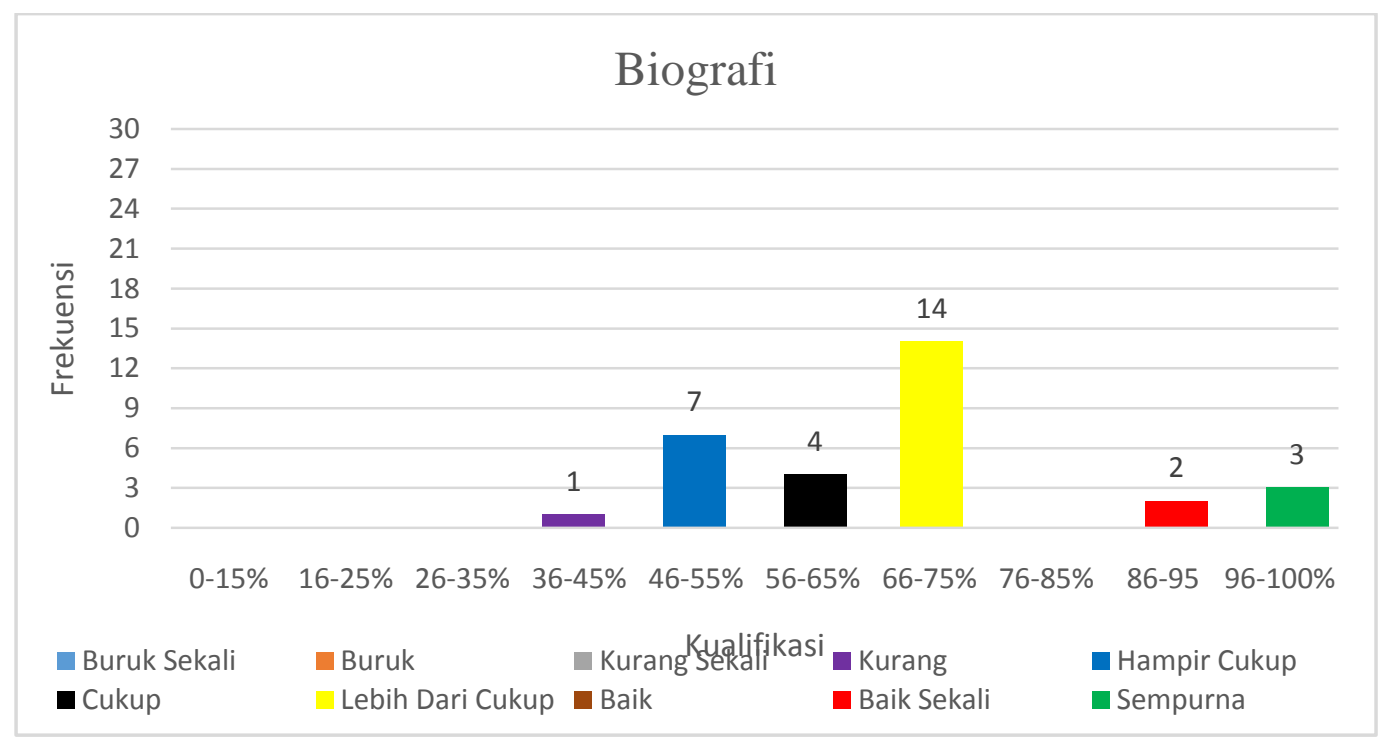

Histogram Kemampuan Siswa Menulis Teks Biografi Siswa Kelas VIII SMP Negeri 2 Kota Solok

Berdasarkan histogram di atas dapat dilihat bahwa kemampuan siswa menulis teks biografi tingkat penguasaan 36-45\% dengan kualifikasi Kurang (K) sebanyak 1 orang yang dilambangkan dengan warna ungu, 46-55 \% dengan kualifikasi Hampir Cukup (HC) sebanyak
7 orang yang dilambangkan dengan warna biru. Tingkat penguasaan 56-65\% dengan kualifikasi Cukup (C) sebanyak 4 orang yang dilambangkan dengan warna hitam, tingkat penguasaan $66-75 \%$ dengan kualifikasi Lebih dari Cukup (LDC) sebanyak 14 orang yang dilambangkan 
dengan warna kuning, tingkat penguasaan 86-95\% dengan kualifikasi Baik Sekali (BS) sebanyak 2 orang yang dilambangkan dengan warna merah. Sedangkan tingkat penguasaan 96-100\% dengan kualifikasi Sempurna (S) sebanyak 3 orang yang dilambangkan dengan warna hijau.

\section{Pembahasan}

Hasil analisis data menunjukkan bahwa kemampuan siswa kelas VIII dalam menulis teks biografi berada pada kualifikasi Lebih Dari Cukup (LDC) dengan nilai rata-rata 69,57 , dengan demikian dapat disimpulkan bahwa siswa kelas VIII SMP Negeri 2 Kota Solok belum mampu mencapai Kriteria Ketuntasan Minimum (KKM) dengan nilai 75,00. Hasil penelitian dari ketiga aspek yang dinilai dalam menulis teks biografi juga menunjukkan bahwa dalam menulis teks biografi sesuai dengan orientasi, peristiwa atau masalah, dan reorientasi, masih mengalami hambatan.

a. Orientasi
Orientasi adalah kalimat yang menjelaskan dari orang yang diceritakan, meliputi siapa nama lengkap atau asli, kapan dan di mana orang tersebut lahir dan meninggal, tempat tinggal, dan nama istri serta anak-anaknya. Kemampuan siswa berdasarkan struktur orientasi tersebut berada pada kualifikasi Lebih dari Cukup (LDC) dengan rata-rata 72,58. Perolehan skor tertinggi 4 dan terendah 2 dari skor maksimal 4 berdasarkan penulisan teks biografi sesuai dengan orientasi. Secara lengkap kemampuan siswa menulis teks biografi sesuai dengan struktur orientasi sebagai berikut: (1) skor 4 sebanyak 11 orang $(35,48 \%)$, (2) skor 3 sebanyak 6 orang $(19,35 \%)$, dan (3) skor 2 sebanyak 14 orang $(45,16 \%)$.

b. Peristiwa/masalah

Peristiwa adalah kalimat yang menjelaskan selengkap-lengkapnya perjalanan hidup, perjuangan, karya, dan penghargaan yang didapatkan oleh orang tersebut. Kemampuan siswa berdasarkan struktur peristiwa atau masalah ini berada 
pada kualifikasi Lebih dari Cukup (LDC) dengan rata-rata 67,74. Perolehan skor tertinggi 4 dan terendah 1 dari skor maksimal 4 berdasarkan penulisan teks biografi sesuai dengan peristiwa/masalah. Secara lengkap kemampuan siswa menulis teks biografi sesuai dengan struktur peristiwa/masalah sebagai berikut: (1) skor 4 sebanyak 8 orang $(25,80 \%)$, (2) skor 3 sebanyak 8 orang $(25,80 \%)$, (3) skor 2 sebanyak 13 orang $(41,93 \%)$, dan skor 1 sebanyak 2 orang $(6,45 \%)$.

c. Reorientasi

Reorientasi merupakan pandangan penulis terhadap tokoh yang diceritakan. Kemampuan siswa menulis teks biografi sesuai dengan struktur reorientasi berada pada kualifikasi Cukup (C) dengan ratarata 62,09. Perolehan skor tertinggi 4 dan terendah 1 dari skor maksimal 4 berdasarkan penulisan teks biografi sesuai dengan reorientasi. Secara lengkap kemampuan siswa menulis teks biografi sesuai dengan struktur orientasi sebagai berikut: (1) skor 4 sebanyak 9 orang
$(29,03 \%)$, (2) skor 3 sebanyak 7 orang $(22,58 \%)$, (3) skor 2 sebanyak 5 orang $(16,12 \%$, dan (4) skor 1 sebanyak 10 orang $(32.25 \%)$.

Berdasarkan hasil penelitian yang telah dilakukan, tes kemampuan siswa menulis teks biografi kelas VIII semester I SMP Negeri 2 Kota Solok dengan jumlah sampel 31 orang tergolong Lebih dari Cukup. Nilai rata-rata yang diperoleh adalah sebesar 69,57. Nilai 69,57 ini berada pada kualifikasi lebih dari cukup (LDC). Dengan hasil yang dicapai ini dibutuhkan upaya yang lebih proaktif lagi oleh guru sehingga mereka lebih mampu memahami teks biografi dalam pembelajaran.

\section{KESIMPULAN DAN SARAN}

Berdasarkan hasil penelitian yang telah diuraikan, dapat disimpulkan bahwa siswa kelas VIII semester I SMP Negeri 2 Kota Solok dalam menulis teks biografi berdasarkan struktur teks mampu menulis teks biografi dengan kualifikasi Lebih dari 
Cukup (LDC) dengan nilai rata-rata 69,57.

Nilai 10 diperoleh oleh 3 sampel $(9,67 \%)$, nilai 9 diperoleh oleh 2 sampel $(6,45 \%)$, nilai 7 diperoleh oleh 14 sampel $(45,16 \%)$, nilai 6 diperoleh 4 sampel $(12,90 \%)$, nilai 5 diperoleh 7 sampel $(22,58 \%)$, nilai 4 diperoleh 1 sampel (3,22\%), sedangkan nilai, 8, 3, 2 dan 1 di peroleh 0 sampel.

Berdasarkan hasil penelitian yang telah diperoleh, maka peneliti memberikan saran kepada: (1) guru bidang studi Bahasa Indonesia yang mengajar di SMP Negeri 2 Kota Solok agar lebih memperhatikan dan lebih memvariasikan metode pembelajaran, (2) bagi siswa-siswa SMP Negeri 2 Kota Solok disarankan agar meningkatkan kemampuan menulis, khususnya menulis teks berdasarkan struktur teks (3) bagi mahasiswa jurusan Bahasa Indonesia disarankan dapat menjadikan skripsi ini sebagai acuan dalam melakukan penelitian yang sejenis, dan 4) pembaca secara umum, disarankan agar bisa menambah wawasan dan pengetahuan tentang cara menulis teks biografi.

\section{DAFTAR PUSTAKA}

Abdurrahman dan Ellya Ratna. 2003. Evaluasi Pembelajaran Bahasa Indonesia. Padang: UNP Press.

Akadiah, Sabarti. Dkk. 1998. Pembinaan Kemampuan Menulis Bahasa Indonesia. Jakarta: Erlangga.

Arikunto, Suharsimi. 2013. Manajemen Penelitian. Jakarta: Rineka Cipta.

Duhita, Arinanda Alma. 2014. "Peningkatan kemampuan Siswa Kelas VII B dalam Meringkas Teks Eksplanasi Melalui Pembelajaran Kooperatif Model Student Teams Achievement Division (Penelitian Tindakan Kelas Pada siwa Kelas VII SMP Negeri 1 Lembang Tahun Ajaran 2013/2014" . Skripsi. Bandung: Pendidikan Indonesia.

Kosasih, E dan Restuti. 2013. Mandiri Bahasa Indonesia. Jakarta: Erlangga.

Mahsun, dkk. 2013. Bahasa Indonesia Wahana Pengetahuan untuk SMP/MTs Kelas VII. Jakarta: Kementrian Pendidikan dan Kebudayaan.

Margono. 2003. Metode Penelitian Pendidikan. Jakarta: Rineka Cipta.

Mulyadi, Yadi. 2014. Bahasa Indonesia untuk SMP-MTs Kelas VIII. Bandung: Yrama Widya.

Priyatni, Endah Tri. Dkk. 2014. Bahasa dan Sastra Indonesia SMP/MTs. Jakarta: Bumi Aksara.

Sugiyono. 2013. Metode Penelitian Pendidikan. Bandung: Afabeta.

Susanto, Ready. 2008. Buku Paket XI SMA/SMK/MAK Bahasa Indonesia Kurikulum 2013. Bandung: Nuansa. 
Tarigan, Hendri Guntur. 1982. Menulis

Sebagai Suatu Keterampilan

Berbahasa. Bandung: Angkasa. 